\title{
El Delito de Conspiración para el Tráfico Ilícito de Drogas: análisis del cuarto párrafo del artículo 296 del Código Penal
}

Fernando Valdez Pimentel

Abogado por la Universidad Nacional Mayor de San Marcos. Maestría por la Universidad Nacional Mayor de San Marcos. Estudios por la Universidad Phillips Marburg de Alemania. Juez Especializado en lo Penal de la Corte Superior de Justicia del Callao.

SUMARIO:

I. Justificación del problema.

II. Aproximaciones a un concepto jurídico-penal del delito de conspiración.

III. Principales características.

IV. Naturaleza jurídica.

V. Sobre la autonomía del delito de conspiración.

VI. El delito de conspiración en el Código Penal de 1991.

VII. Morfología típica y técnica legislativa del artículo 296 del Código Penal.

VIII. Análisis del cuarto párrafo del artículo 296 del Código Penal.

IX. Sobre la aplicación de las agravantes del artículo 297 al cuarto párrafo del artículo 296 del Código Penal. ¿Delito de conspiración para el TID en su modalidad agravada?

1. Principio de excepcionalidad.

2. Autonomía del delito de conspiración.

3. Tipificación comparativa del delito de conspiración.

4. Principio de lesividad.

5. Principio de proporcionalidad.

6. Naturaleza configurativa de las agravantes.

7. Prohibición de la analogía in malam partem.

8. Interpretación restrictiva de las leyes que restringen derechos. 


\section{RESUMEN:}

El autor realiza un análisis de lo que debe entenderse por el delito de conspiración en un marco general, para posteriormente interpretar los delitos conspirativos en la legislación penal, haciéndose énfasis en el delito conspirativo para el tráfico de drogas. Asimismo, centra su atención en responder si es dogmáticamente posible y constitucionalmente legítimo aplicar las agravantes del artículo 297 al cuarto párrafo del artículo 296 del Código Penal, concluyendo que no lo es.

Palabras clave: Conspiración, actos preparatorios, concertación, agravantes, principios, proporcionalidad, bien jurídico.

\footnotetext{
ABSTRACT:

The author analyzes what should be understood by the crime of conspiracy in a general framework, to later interpret conspiracy crimes according to criminal law, emphasizing the crime of conspiracy for drug trafficking. Likewise, he focuses his attention on answering whether it is dogmatically possible and constitutionally legitimate to apply the aggravating circumstances of article 297 to the fourth paragraph of article 296 of the Penal Code, concluding that it is not.

Keywords: conspiracy, preparatory acts, collusion, aggravating circumstances, principles, proportionality, legal asset.
}

\section{JUSTIFICACIÓN DEL PROBLEMA}

Uno de los temas recurrentes que está siendo materia de investigación y juzgamiento es el delito de conspiración para el tráfico ilícito de drogas - TID. Las fiscalías especializadas en los diferentes casos emblemáticos, como el de Gerald Oropeza López', Gerson Gálvez Calle y Renzo Espinoza Brissolesi ${ }^{2}$ - cabecillas de la banda "Barrio King"一, "Teniente del Ejército Peruano en el VRAEM", "droga bamba o yeso", etcétera, en los que no se encontró droga, han logrado, sin embargo, gracias a las diferentes técnicas de investigación - como el levantamiento del secreto de las comunicaciones o el servicio de inteligencia, encontrar claros indicios o pruebas de que dos o más personas han concertado o están en proceso de concertación para traficar droga o realizar alguna actividad vinculada al tráfico ilícito de drogas, prescrito en el artículo 296 del Código Penal — en adelante, el "Código"- su exitosa persecución. El Ministerio Pú-

1. Expediente $N^{\circ} 122-2015$ a cargo del Primer Juzgado de Investigación Preparatoria Nacional y de la Segunda Fiscalía Corporativa Especializada en Criminalidad Organizada de Lima, Cuarto Equipo. La Fiscalía lo acusa por el delito de conspiración para el tráfico ilícito de drogas en su modalidad agravada — ser cabecilla de una organización criminal-y solicita 29 años de privación de la libertad. Para mayor referencia: "Audiencia De Control De Acusación Contra Presunta Organización Criminal Liderada Por Gerald Oropeza", YouTube (Justicia TV, 3 de octubre de 2018), https://www.youtube.com/watch?v=2nD1h8XwOH0.

2. A quienes se le acusa, entre otros, por el delito de conspiración para el tráfico ilícito de drogas en la modalidad agravada por forma parte de una organización criminal. Para mayor referencia: "PJ dicta prisión preventiva para 'Renzito'", YouTube (Justicia TV, 26 de enero de 2016), https://www.youtube.com/watch?v=CnZc-D8yugc\&t=324s.

3. Expediente $\mathrm{N}^{\circ}$ 33-2015 a cargo del Segundo Juzgado de Investigación Preparatoria Nacional y de la Segunda Fiscalía Corporativa Especializada en Criminalidad Organizada de Lima, Segundo Equipo. Caso "El Soldado", difundido en el programa Panorama: "Teniente EP cobraba cupos a narcos en el VRAEM - TV - 5 - 25 OCT 15", YouTube (RESUMEN, 25 de octubre de 2015), https://www.youtube.com/watch?v=gehzvRdNpsk.

4. Expediente $\mathrm{N}^{\circ} \mathbf{1 5 6}-2014$, caso en el cual se intervino a cinco personas en la ciudad de Pisco con aproximadamente 50 kilos de una sustancia blanquecina tipo ladrillo, pero que luego de los análisis respectivos se confirmó que no era pasta básica de cocaína, sino yeso. Sandra Gutierrez lquise, "Investigados Que Transportaban Yeso Son Condenados Por Conspiración AI Tráfico De Drogas," LP, 24 de julio de 2018, https://legis.pe/conspiracion-trafico-drogas-transportando-yeso/. 
blico en todos estos casos ha formulado acusación por el delito de conspiración para el tráfico ilícito de drogas - tipificado en el cuarto párrafo del artículo 296- en su modalidad agravada. Principalmente, aplican las agravantes del numeral 6 -que el hecho es cometido por una pluralidad de personas o por una organización criminal-y la del numeral 7 - que la droga a comercializarse exceda las cantidades establecidas- del artículo 297 del Código.

Sin mayor reparo, se da por asumido por los operadores jurídicos que el artículo 296 del Código es el tipo base del delito de TID. ${ }^{5}$ Esto es porque la norma penal matriz o genérica define qué actos configuran dicho delito. ${ }^{6}$ En consecuencia, se presupone que los demás tipos penales sobre el tráfico de drogas están vinculados de forma directa o indirecta con el artículo 296, ya sea añadiendo una circunstancia agravante o atenuante. Sin embargo, el artículo 296 no tipifica un solo delito, sino cuatro delitos diferentes: se trata de un texto legal complejo donde el legislador - utilizando una mala técnica legislativa - ha buscado reunir en un solo dispositivo legal cuatro modalidades posibles de intervenir en el proceso o circuito estratégico, productivo y de comercialización ilegal de drogas fiscalizadas ${ }^{7}$; pese a que las conductas tipificadas tienen estructura y características diferentes.

Si bien la tipificación del delito de conspiración para TID se ubica en el artículo 296, esto no implica necesariamente que forme parte de él, porque dogmáticamente responde a una naturaleza jurídica distinta a la del delito de TID en su fase consumada. En tal sentido, la aplicación de las agravantes del artículo 297 a cada uno de los supuestos del artículo 296, por lo menos, merece una especial reflexión, con miras a evitar excesos punitivos, por la falta de claridad en la delimitación teórica. En consecuencia, se hace necesario un estudio que responda a las siguientes interrogantes: ¿qué debe entenderse por el delito de conspiración? ¿Cuál es la naturaleza jurídica del delito de conspiración? ¿Es correcto que la tipificación del delito de conspiración se ubique en el mismo tipo penal que regula la consumación delictiva? ¿En nuestra legislación penal existe el delito de conspiración en su modalidad agravada? ¿Es constitucionalmente legítima y dogmáticamente posible la aplicación de las circunstancias agravantes del artículo 297 al cuarto párrafo del artículo 296 del Código? En otras palabras, ¿es jurídicamente factible la aplicación de las agravantes establecidas en el artículo 297 del Código al delito de conspiración para el tráfico ilícito de drogas? Responder a cada una de ellas es el objetivo que pretende el presente trabajo.

\section{APROXIMACIONES A UN CONCEPTO JU- RÍDICO-PENAL DEL DELITO DE CONSPI- RACIÓN}

Tenemos a Beccaria como el antecedente más próximo que ha escrito sobre el concepto jurídico penal de conspiración. En su obra cumbre, señala: "aunque las leyes no castiguen la intención, no por eso decimos que un delito cuando empieza por alguna acción que manifiesta la voluntad de cometerlo no merezca algún castigo, pero siempre menor a la misma comisión de él". ${ }^{8}$ Por otro lado, los diccionarios jurídicos más connotados nos dan ideas sobre el concepto. Así, por ejemplo, el diccionario de Cabanellas señala que "es el acto de unirse secretamente algunos o muchos contra su soberano o gobierno,

5. Véase Acuerdo Plenario N³-2008/CJ-116.

6. En forma crítica, Víctor Prado Saldarriaga, Criminalidad Organizada - Parte Especial (Lima: Instituto Pacífico, 2016), 137.

7. Ibíd.

8. César Beccaria, Tratado de los delitos y de las penas (Madrid: Fondo Editorial Universidad Carlos III de Madrid, 2013 ), 76. 
pero también es la conjuración o confabulación de varias personas contra alguno, con el objeto de perderle o causarle daño". 9 Sin embargo, es el diccionario Black el que nos confiere una definición estrictamente penal y precisa de conspiración: "es una combinación o confederación entre dos o más personas con el propósito de cometer, por sus esfuerzos conjuntos, algún acto ilegal o criminal".10

En el mundo jurídico, se nos hace muy difícil proponer un concepto al margen de la Ley, dificultad que se acrecienta porque nuestro Código Penal no propone una definición; sin embargo, tomaremos como referencia a la legislación comparada, a la jurisprudencia y a los autores que sobre el tema han escrito que son pocos-, para aproximarnos a la definición. Sin duda, una de las referencias legislativas de gran influencia en nuestro país es la española. Así, el artículo 17.1 del Código Penal español señala: "Il]a conspiración existe cuando dos o más personas se conciertan para la ejecución de un delito y resuelven ejecutarlo". Interpretando el mencionado dispositivo legal, el Tribunal Supremo Español, en la sentencia $N^{\circ}$ 144/2018 ${ }^{11}$ del 22 marzo de 2018, señaló lo siguiente:

"La conspiración pertenece a una fase del iter criminis anterior a la ejecución, por lo que tiene hasta cierto punto naturaleza de acto preparatorio, y se ubica entre la ideación impune y las formas imperfectas de ejecución, como una especie de coautoría anticipada que determinados autores des- plazan hacia el área de la incriminación excepcional de algunas resoluciones manifestadas, pero que, en todo caso, se caracteriza por la conjunción del pactum scaeleris 0 concierto previo, y la resolución firme o decisión sería de ejecución".

En similar sentido, la Corte Suprema de Justicia de la República, interpretando el último párrafo del artículo 296 del Código, en el Recurso de Nulidad N ${ }^{\circ}$ 2350-2009 del 18 de marzo del año 2010, indicó:

"(...) ahora bien, los actos de conspiración importan una forma de coautoría anticipada, en cuya virtud dos o más personas se conciertan para la ejecución de un delito y resuelven realizarlos (...) por lo que tendrán esa condición los que piensan intervenir como autores en fase ejecutiva del referido delito y reúnen los requisitos para ello; que por consiguiente, como son formas de participación intentada en el delito o formas preparatorias punibles de participación, si la conducta efectivamente acordada se lleva acabo se está ante un supuesto típico distinto (...)"..12

Es decir, el delito de conspiración pertenece a la expresión de la expansión del Derecho Penal, se encuentra en la categoría de los delitos excepcionales y consiste en la punición de determinadas conductas preparatorias debido a su alta peligrosidad para los bienes jurídicos. Se trata de una fase del iter criminis anterior a la ejecución, entre la mera ideación impune y

9. Guillermo Cabanellas de las Cuevas, Diccionario Jurídico Elemental (Buenos Aires: ELIASTA S.R.L., 11 ed., 1999), 250.

10. Henry Campbell Black, Black's Law Dictionary (Eagan: West Publishing, $2^{\circ}$ ed., 1910), https://espanol.thelawdictionary.org/.

11. Véanse Sentencias del Tribunal Supremo N ${ }^{\circ} 77 / 2007,321 / 2007,1140 / 2010,234 / 2017$, entre otras.

12. En forma similar nuestra Corte Suprema, en el Recurso de Nulidad N 921-2012-Amazonas, que refiriéndose a tema dijo: "(...) el delito de conspiración es una combinación o confederación entre dos o más personas con el propósito de cometer, por sus esfuerzos conjuntos algún acto ilegal o criminal, dicho delito pertenece a la fase del iter criminis anterior a la ejecución del delito (...)". 
las formas ejecutivas imperfectas, por ello que se considere una especie de coautoría anticipada. ${ }^{13}$ Consiste en participar de una concertación para realizar actos delictivos futuros. ${ }^{14}$ Los conspiradores, pues, se deben limitar a idear y bosquejar acciones o estructuras criminales que se materializarán en un futuro próximo o mediato. Ellos realizan únicamente actos preparatorios donde lo esencial es el intercambio o el acuerdo de voluntades en relación a un proyecto delictivo común. ${ }^{15}$

Cuello Contreras dice que la conspiración supone un proceso en el que varios sujetos se encuentran $y$, del intercambio de ideas y propósitos, nace -entre ellos- una decisión firme y precisa de ejecutar el delito; es decir, de hacer algo juntos que de otra manera no harían por separado ${ }^{16}$. En este sentido, se habla de actos preparatorios intensos o intensificados.

En este caso, la meta —el delito- es decisión de todos los conspiradores, sin que pueda hablarse de corrupción en el sentido de que alguno determine a otro, o todos se determinen entre sí, a realizar algo contrario a su personalidad. ${ }^{17}$ Esta infracción penal es de mera actividad y se perfecciona, pues, con el acuerdo de los conspiradores. Por lo tanto, no será necesario para la realización típica que el proyecto criminal futuro se implemente materialmente, ni que su concreción sea exitosa o fracase, o que en su ejecución intervenga directa o indirectamente el conspirador. ${ }^{18}$

La razón de la punición anticipada radica en que lo posterior a los actos preparatorios se dirige a la realización de un delito muy grave. La gravedad del delito es lo que fundamenta la conspiración; de allí que hablar de conspiración para delitos leves sería no sería posible. Se parte de la premisa, dada la gravedad del delito, de que esperar el comienzo de la ejecución resulta ineficaz para su prevención. El legislador adelanta las barreras de la punición y se sitúa antes de la tentativa, es decir, antes de que se inicie la realización del tipo. Se trata, por lo tanto, de un motivo de prevención de la peligrosidad evidenciada socialmente con conductas dirigidas a dar inicio a un delito. Ahora bien, no se trata de prevenir cualquier conducta previa a un delito, sino solo aquellas que, dada su manifestación, nos llevan de forma inequívoca a la comisión de un delito.

Resumiendo, podríamos decir que la conspiración surge de la existencia de un concierto previo entre dos o más personas; la finalidad del concierto necesariamente debe ser delictiva; $y$, tal finalidad debe ser expresada en el mundo exterior mediante actividades manifiestamente criminales -actos preparatorios intensificados- - Y en dicha medida, mientras

13. Santiago Mir Puig, Derecho Penal, parte general (Buenos Aires: IbdeF, 10ed., 2016), 351. La conspiración constituye una forma previa a la coautoría, es una coautoría anticipada. Las consecuencias de asumir el delito de conspiración en una coautoría anticipada son dos: a) solo pueden ser sujetos de la conspiración quienes reúnen, según el tipo penal, las condiciones necesarias para ser autores del delito proyectado y b) la resolución de ejecutar el hecho debe constituir una resolución firme de ser coautor de un delito en concreto.

14. Saldarriaga, Criminalidad Organizada... p. 154

15. Victor Prado Saldarriaga, "Tráfico ilícito de drogas y conductas conexas", http://perso.unifr.ch/derechopenal/assets/files/articulos/a_20080526_68.pdf.

16. Joaquín Cuello Contreras, La conspiración para cometer el delito: interpretación del art. 4, I, CP (los actos preparatorios de las participación) (Barcelona: Bosch, 1987), 14.

17. Ibíd., 16.

18. Víctor Prado Saldarriaga, "Tráfico ilícito de drogas y conductas conexas". 
no se adopte la decisión de cometer el delito no puede existir conspiración y, a lo sumo, habrá un acto preparatorio impune. ${ }^{19}$ Como se dijo, es una especie de coautoría anticipada que determinados autores desplazan hacia el área de la incriminación excepcional de algunas resoluciones manifestadas; pero que, en todo caso, se caracteriza por la conjunción del pactum scaeleris o concierto previo, y la resolución firme de su ejecución.

\section{PRINCIPALES CARACTERÍSTICAS}

Es la jurisprudencia y los teóricos españoles quienes mejor han trabajado este tema. Así, en la Sentencia del Tribunal Supremo español $N^{\circ} 886 / 2007$, tal órgano indicó que el delito de conspiración siempre requiere un concierto de voluntades, con decisión dificultosa y concreta de realización de un delito conforme a un proyecto viable. Entre los elementos más destacados que lo caracterizan, señaló:

a) Ha de mediar un concierto de voluntades entre dos o más personas;

b) Una orientación de todas las voluntades o propósitos al mismo hecho delictivo;

c) La decisión definitiva y firme de ejecutar un delito, plasmada en un plan concreto y determinado;

d) La actuación dolosa de cada concertado, que debe ser consciente, asumir lo que se pacta y la decisión de llevarlo a cabo;

e) La viabilidad del proyecto delictivo;

f) Que no se haya dado comienzo a la ejecución delictiva; $y$, g) La existencia de un lapso de tiempo relevante entre el proyecto y la acción que permita apreciar una mínima firmeza de la resolución, ya que no puede ser repentina.

En cuanto al número de participantes, la conspiración por lo general se refiere a un acuerdo entre dos o más personas para cometer un delito. Cabe precisar que la sola existencia de dos o más personas no tipificaría el delito de conspiración, puesto que dicha consideración infringe el principio de proscripción de responsabilidad objetiva - artículo VII del Título Preliminar del Código-, sino que se hace necesario el concierto común y delictivo de todos los agentes. ${ }^{20}$ Tal como es configurada la conspiración, no existe conspiración individual — de una sola persona-, sino conspiración plural; los sujetos que conspiran han de acordar resolver colectivamente la ejecución de un delito: se precisa el acuerdo plural o colectivo, de manera que la resolución criminal es conjunta, fruto de una deliberación por parte de todos los conspiradores. ${ }^{21}$ Ahora bien, por lo menos una persona -el coconspirador- debe ejecutar un acto manifiesto.

Un acto manifiesto es un acto con alta probabilidad delictiva del delito acordado, es más que un acto de planear un delito. Sin embargo, no tiene que ser un acto criminal en sí: podría ser algo tan lícito como hacer una llamada telefónica, rentar un auto o escribir una carta, pero con una finalidad delictiva previamente acordada. Ahora bien, el acuerdo entre los coconspiradores no tiene que ser un acuerdo explícito, deta-

19. Fernando Sequeros Sazartonil, El delito de tráfico de drogas en el ordenamiento jurídico (Madrid: La Ley, 2000), 323 y ss. Es incompatible con la iniciación ejecutiva material del delito, que supondría ya la presencia de coautores o partícipes de un delito intentado o consumado, pero requiere, en todo caso, que los conspiradores desarrollen una actividad precisa y concreta con realidad material y tangible que ponga de relieve la voluntad de delinquir, sin recurrir a tan solo meras conjeturas o suposiciones. Se caracteriza por la conjunción del concierto previo y la firme resolución, previo análisis probatorio tanto subjetivo como objetivo.

20. En este sentido resolvió el Acuerdo Plenario N 3-2005/CJ-116, sobre los alcances del artículo 297, numeral 6 del Código Penal e intervención de tres o más agentes, y también el Acuerdo Plenario Nº 3-2008/CJ-116.

21. Miguel Polaino Navarrete, Lecciones de Derecho penal. Parte especial, adaptadas a la ley orgánica 5/2010 de Reforma del Código penal (Madrid: Tecnos, tomo II, 2011), 214. También en el mismo sentido Joaquín Cuello Contreras, Op. Cit., 17. 
llado o formal para cometer el delito. Se podrá deducir si se ha conspirado o no en función a los hechos y a las circunstancias de cada caso.

Por otro lado, debemos destacar y enfatizar que el delito de conspiración pertenece al régimen de excepcionalidad, de tercera velocidad o derecho penal del enemigo y, por ende, la interpretación debe ser lo más restrictiva posible. Deben utilizarse todas las herramientas que la historia jurídica y la dogmática nos han dado para controlar los excesos punitivos. Es en circunstancias como estas en las que debe prevalecer, sin excepción, todos los principios y garantías pro homine. Joshi Jubert señala: "[l] a configuración por parte de la doctrina y la jurisprudencia mayoritaria de este delito como de peligro abstracto o de mera actividad y de consumación anticipada ha sido determinante para no admitir o hacerlo de forma excepcional (...)".22

\section{NATURALEZA JURÍDICA}

Este delito, como ya se dijo, tiene una naturaleza excepcional. En consecuencia, en el marco de un Estado Constitucional, no cabe otra que limitar su interpretación y aplicación. En caso contrario, se corre el riesgo de punir meras imaginaciones o pensamientos - cogitationis poenam nemo patitur-; lo que nos llevaría a un Derecho Penal totalitario o de autor. Solo por razones de política criminal se comprende por qué el legislador castiga conductas preparatorias; a juicio de Jescheck, éstas deben cumplir con dos características: a) Se trata de tipos penales cuya peculiaridad demanda una intervención especialmente precoz, de lo contario, no se conseguiría nada mediante la pena; $y$,

b) Son supuestos típicos especialmente peligrosos. ${ }^{23}$

Para Mir Puig, la razón del castigo de los actos preparatorios es la especial peligrosidad que encierra la implicación de otras personas en el proyecto criminal. ${ }^{24}$ Ésta ha de verse, pues, en la peligrosidad objetiva de determinados actos dirigidos a consumar el delito, en la medida en que dicha peligrosidad se manifiesta ya ex ante..$^{25}$

Jakobs sostiene, en tanto que la preparación no se limita a los planes de un sujeto singular sino que se objetiva mediante el planteamiento común de varios sujetos, el Derecho positivo la pune en varios casos, sin sujetarse a los límites que traza para el Derecho Penal el estatus de ciudadano que delinque. ${ }^{26}$

El delito de conspiración tiene naturaleza jurídica de ser una forma de resolución manifiesta que, dentro de la teoría del delito, pertenece al ámbito de los actos preparatorios - aunque existen algunos autores que prefieren ubicarlo en un estadio intermedio, entre la fase interna y los actos preparatorios propiamente dichos, ${ }^{27}$ algo así como actos pre preparatorios-; y, siguiendo el iter criminis, se ubica en una fase anterior a la ejecución, es decir, entre la ideación impune y la tentativa. Ahora bien, esta tipología delictiva se presenta, exclusivamente, mien-

22. Ujala Joshi Jubert, Los delitos de tráfico ilícito de drogas (Barcelona: Bosch. 1999), 227.

23. Hans Jescheck y Thomas Weidend, Tratado de Derecho Penal, parte general. Trad por Miguel Olmedo Cardenete (Granada: Comares S.L., 2002), 562 y ss.

24. Mir Puig, Derecho Penal... P.351.

25. Ibid, p. 349.

26. Vemos que Jakobs nos refiere que la punibilidad de los actos preparatorios no es digna del derecho penal del ciudadano; dejando entrever que esta tipología pertenece al derecho penal del enemigo. Günther Jakobs, Derecho Penal, parte general. Trad. Cuello Contreras y Serrano González de Murillo (Madrid: Marcial Pons. 1997), 858.

27. Es el caso, por ejemplo, de Fernando Sequeros Sazartonil, El delito de tráfico... p.320 y ss. 
tras el delito finalidad o delito por el cual se ha conspirado no se comete ni en su modalidad de tentativa, pues de hacerlo queda absorbido por este último - artículo 16 del Código-. No es aplicable, por ende, cuando el delito proyectado ya se ejecutó o está en proceso de ejecución, pues en ese caso la tentativa absorbería la conspiración. ${ }^{28}$ El Tribunal Supremo Español, en la sentencia $N^{\circ} 144 / 2018$, dijo que la conspiración, caracterizada por la conjunción del concierto previo y la firme resolución, es incompatible con la iniciación de la ejecución material del delito. Tal infracción desaparece y se disipa como forma punible sancionable cuando el hecho concertado pasa a vías ulteriores de realización - cualquiera que éstas sean-, ya que entonces esas ejecuciones absorben por completo los conciertos e ideaciones anteriores al ser puestas en marcha.

En el mismo sentido, la Corte Suprema de Justicia de la República, en el Recurso de Nulidad N ${ }^{\circ}$ 921-2012-Amazonas, en el que se había condenado en primera y segunda instancia tanto por el delito de conspiración para el tráfico ilícito de drogas como por el delito de tráfico ilícito de drogas — una aberración jurídica-, manifestó que el delito de conspiración pertenece a la fase del iter criminis anterior a la ejecución del delito de tráfico ilícito de drogas; es decir, no es aplicable la conspiración cuando el delito proyectado ya se ejecuta, pues en este caso la tentativa absorbería la conspiración. Por lo tanto, es un tipo penal subsidiario o residual.

En otras palabras, si los sujetos concertados dan inicio a la realización del hecho típico, inmediatamente debemos entender que los partícipes han traspasado el ámbito de los actos preparatorios $y$, por ende, la conspiración, ingresando a la esfera normalmente sancionable por el Derecho Penal - esto es, la tentativa, frustración, consumación o agotamiento de un delito determinado-. Por lo tanto, una vez que los partícipes realizan hechos directos para consumar el plan criminal, ya no cabe castigar la conducta a título de conspiración, sino, se debe imponer la sanción establecida para el tipo penal especifico, de acuerdo a la etapa de ejecución del delito en que éste se haya desarrollado - a diferencia de los países que siguen la tradición del common law, en los que es posible la punibilidad de los dos delitos a su vez-. Por ejemplo, no cabe que se sancione por el delito de conspiración para el sicariato -artículo 108-D-y a su vez se sancione por el delito de sicariato - artículo 108-C - . Se presenta, pues, la figura del concurso aparente de leyes que debe ser resuelto mediante el principio de consunción; es decir, que el delito fin consume o absorbe al de conspiración.

Es un delito de mera actividad y se emplea la técnica legislativa del peligro abstracto porque no existe un peligro inminente de lesión a un bien jurídico. Precisamente en este punto se debate su legitimación, porque nuestro Código Penal requiere de la lesión o puesta en peligro de un bien jurídico. Por otro lado, debemos decir que, en términos legales, la conspiración es de personas, siendo no relevante la existencia de una organización de por medio; aunque es verdad que una organización delictiva, casi siempre antes de la comisión de determinado delito, cometerá un acto de conspiración como fase previa.

Por otro lado, en la parte subjetiva del delito, es un delito doloso por naturaleza; por ende, se exige que haya prueba en un doble sentido ${ }^{29}$ :

a) Que se acredite que en el delito que se pretende cometer concurrían todos los elementos de hecho que se requieran para esa figura de infracción principal; $y$,

b) Que se acredite la presencia de los requisi-

28. Nelly Aurora Castro Olaechea, "Ensayo sobre la conspiración en el Código Penal Peruano", https://docplayer. es/43005851-Ensayo-sobre-la-conspiracion-en-el-codigo-penal-peruano.html. En este mismo sentido, Víctor Prado Saldarriaga, Criminalidad Organizada - Parte Especial, 155.

29. Sentencia del Tribunal Supremo español N $120 / 2009$. 
tos que el tipo penal exige en su definición de la conspiración, a saber, que dos o más personas se pongan de acuerdo - - "se conciertan"- para la ejecución de un delito y que resuelvan ejecutarlo.

\section{SOBRE LA AUTONOMÍA DEL DELITO DE CONSPIRACIÓN}

El Tribunal Supremo español, en su sentencia $N^{\circ} 1129 / 2002$, respecto de la autonomía de la conspiración, dijo que se trata de un delito de características híbridas, pues si bien se le ha considerado en muchas ocasiones como delito de dinámica propia, no es fácil olvidar que, al mismo tiempo y de una forma indefectible, es subsidiario o dependiente de otro que podemos llamar principal, o lo que es lo mismo, podríamos decir que se trata de un delito simplemente "mediato" y no "inmediato"; de características parecidas, según una parte de la doctrina, a lo que se ha dado en llamar una tentativa de peligro. Por tanto, la independencia tipológica de estos delitos es más aparente que real. ${ }^{30}$

Polaino-Orts es de la idea que los delitos de conspiración como provocación son un delito de consumación anticipada con plena autonomía. ${ }^{31}$ Mir Puig sostiene que la conspiración es, en sí misma, un conjunto de delitos distintos al hecho consumado a que se dirigen; mas, en cuanto son formas previas de codelincuencia, son solo delitos dependientes, no autónomos, como los tipos de participación respecto del hecho del autor. ${ }^{32}$

Por nuestra parte, somos de la opinión de que en este tema debemos diferenciar su autonomía desde dos perspectivas: autonomía respecto de la naturaleza jurídica y autonomía respecto de su tipificación.

En cuanto a la primera, la autonomía es plena, porque son actos preparatorios punibles: por ende, como fase dentro del iter criminis es independiente de la ejecución y la consumación. ${ }^{33}$ La conspiración es un delito independiente del delito fin que se va a perpetrar y dentro del iter criminis tiene una fase propia que el legislador tiene por bien castigar como un delito más. Es un delito ejemplo de la tendencia punitiva estatal, es un adelantamiento de las barreras de punibilidad.

En cuanto a la segunda, posee una autonomía relativa, porque no existe el delito de conspiración en sí, sino que siempre será conspiración de o para algo. Son los tipos penales quienes sirven como criterios de orientación para determinar conspiración de qué delito es. Por ejemplo, nuestro Código Penal, en su artículo 108-D, tipifica el delito de conspiración para el sicariato; en el 296, conspiración para el tráfico ilícito de drogas; en el 349, conspiración para el delito de rebelión, sedición o motín; etc.

30. Interpretando la legislación penal española, señala: "(...) porque, de un lado, el art. 17.1 nos indica que la conspiración siempre habrá de ir dirigida a la "ejecución de un delito" y, de otras, porque el módulo cuantitativo de la pena que pueda corresponder se hace depender de la que haya de aplicarse al delito pretendido (delito "matriz"), en este caso concreto, al tratarse de tráfico de drogas, con la pena inferior en uno o dos grados a los previstos para aquél (art. 373)".

31. Miguel Polaino-Orts, Lo verdadero y lo falso del Derecho penal del enemigo (Lima: Grijley, 2009), 364.

32. Véase Mir Puig, Derecho Penal... p. 351.

33. Como se dijo, los actos preparatorios punibles han sido en ocasiones interpretados como específicas formas de "tentativa de participación"; es decir, como inicio de las formas de participación que ya conocemos. De ser así, debería regir la accesoriedad limitada de la participación, pero no sería posible porque por definición no ha dado comienzo todavía el tipo. Se exige entonces la accesoriedad sólo hipotéticamente, como afirma Jescheck, si bien es preferible entender que nos hallamos ante delitos, pero que no son autónomos — postura defendida por Mir Puig-, en cuanto dependen del delito al que vienen a preparar; y así la pena del delito al que van dirigidos sirve de punto de referencia para la penalidad de los actos preparatorios. 


\section{EL DELITO DE CONSPIRACIÓN EN EL CÓ- DIGO PENAL DE 1991}

En el Código Penal vigente no encontramos referencia alguna en la parte general - como lo hay en España y en Chile-, acerca de lo que debe entenderse por conspiración; pese a que en su parte especial, desde su promulgación en el año 1991, se ha sancionado conductas bajo esta nomenclatura: por ejemplo, la conspiración para cometer los delitos de rebelión, sedición o motín - artículo 349-. La tendencia actual de la legislación penal peruana es de incorporar la figura de conspiración a nuevos delitos, pero regulándolos en la parte especial del Código. ${ }^{34}$ En efecto, además de la conspiración para la rebelión, sedición o motín; en el año 2007 se incorporó el de conspiración para el TID —artículo 296-; en 2015 se incorporó a la Ley 25475 el artículo 6-B, mediante el cual se añadió el delito de conspiración al terrorismo; también en el año 2015, mediante el artículo 108-D del Código, se configuró el delito de conspiración para el sicariato.

Como ya se manifestó anteriormente, la incorporación de estas formas de preparación "autónoma" en el ámbito punible se debe a consideraciones político-criminales, antes que a aspectos jurídico-dogmáticos; pues si se respetaran estos últimos, ninguno de los delitos mencionados resistirían un análisis desde un Derecho Penal acorde al Estado Constitucional, ya que invade el fuero previo a la ejecución típica del bien jurídico, es decir, se aleja en demasía a la efectiva lesividad objetiva del bien jurídico penal. Si bien los delitos de peligro - sobre todo el peligro concreto- están legitimados en el Derecho Penal moderno; el concepto de peligrosidad de los actos preparatorios es muy remoto. Habrá que advertir que la razón fundamental del castigo de los actos preparatorios punibles es la especial peligrosidad que encierra la implicación de otras personas en el proyecto criminal.

\section{MORFOLOGÍA TÍPICA Y TÉCNICA LEGIS- LATIVA DEL ARTÍCULO 296 DEL CÓDIGO PENAL}

Los cuatro supuestos fácticos que tipifica el artículo en mención son los que se describen a continuación:

a) El primer párrafo se refiere a la promoción, favorecimiento o facilitación del consumo ilegal de drogas, mediante la fabricación o tráfico.

b) El segundo párrafo describe la posesión de drogas para su tráfico.

c) El tercer párrafo hace referencia a la comercialización de materias primas o insumos destinados a la elaboración y actos afines de la droga.

d) El último párrafo contempla la conspiración para promover, favorecer o facilitar el tráfico de drogas.

Analizando, diremos que el legislador ha utilizado diferentes formas de tipificación en los cuatro supuestos. Es así como, en el supuesto regulado en el párrafo primero, se presenta la técnica jurídica del delito de peligro concreto. ${ }^{35}$

34. En nuestra opinión, solo es cuestión de tiempo para que se incorpore el delito de conspiración en el rubro de los delitos cometidos por funcionario públicos, específicamente en los de corrupción de funcionarios. La Corte Suprema ya dijo que el delito de "colusión simple" es un delito de conspiración; véase Casación N542-2017-Lambayeque, emitida el 3 de mayo de 2019.

35. Aunque en opinión de Bramont-Arias Torres y García Cantizano, este supuesto supondría un delito de peligro abstracto y por ende no admite tentativa. Véase Luis Alberto Bramont-Arias Torres y María del Carmen García Cantizano, Manual de Derecho penal, parte especial (Lima: San Marcos, $3^{\circ}$ ed., 1997), 526. El autor nacional Frisancho Aparicio no desarrolla una posición clara al respecto, limitándose en señalar que la consumación se configura cuando el autor coloque en una situación de riesgo al bien jurídico - Cfr. Manuel Frisancho Aparicio, Tráfico ilícito de drogas y lavado de dinero (Lima: Jurista Editores, 2002), 88 y ss.-. Por otro lado, quien opina que este supuesto configura un delito de peligro concreto, es el Juez Supremo Prado Saldarriaga. Véase. Víctor Prado Saldarriaga, Comentarios al Código Penal de 1991 (Lima: Alternativa, 1999), 144. 
En cambio, los actos tipificados en el párrafo segundo están configurados como una conducta de peligro abstracto; y las consideradas en los párrafos tercero y cuarto constituyen la criminalización autónoma de formas específicas de participación y de actos preparatorios. ${ }^{36}$

Empero, la redacción actual del artículo 296 del Código es una muestra de deficiente técnica legislativa, porque son cuatro tipos de conductas delictivas diferentes. Cada una de ellas posee características propias que aluden a elementos típicos y momentos consumativos diferenciables, por lo que su inclusión en una sola disposición no es técnicamente adecuada. En este mismo sentido opina Balladares Aparicio, quien menciona que en el artículo 296 no hay un tipo básico modelo. ${ }^{37}$ Refiriéndose a la ubicación del último párrafo del artículo 296, Prado Saldarriaga muestra su desacuerdo señalando que lo objetable radica en la ubicación sistemática de esta conducta criminal, pues, en su opinión, este tipo debió ser parte integrante del artículo 317 del Código para que su espectro preventivo se irradie sobre toda manifestación de criminalidad. ${ }^{38}$

\section{ANÁLISIS DEL CUARTO PÁRRAFO DEL AR- TÍCULO 296 DEL CÓDIGO PENAL}

Fue en el año 2007 cuando este delito empieza a formar parte de nuestra legislación con el ob- jetivo de combatir eficazmente el TID. A juicio de Prado Saldarriaga, la modificación más significativa que aportó el Decreto Legislativo 982 fue la inclusión del cuarto párrafo ${ }^{39}$ del artículo 296; y tal decisión del legislador es oportuna y responde a la influencia contemporánea de las estrategias de la política criminal internacional contra la delincuencia organizada. ${ }^{40}$

Como ya dijimos anteriormente, la conspiración exige la participación de dos o más personas que se conciertan para delinquir. En el caso que nos ocupa, tal conspiración debe dirigirse a la promoción y/o favorecimiento al comercio ilícito de las sustancias prohibidas ${ }^{41}$; por ende, si la concertación delictiva se destina a la comisión de otros hechos punibles, ha de descartarse el supuesto in examine. ${ }^{42}$ La Sala Penal Permanente de la Corte Suprema, en la sentencia recaída en el Recurso de Nulidad N 2350-2009-Ayacucho de fecha 18 de marzo de 2010, ha señalado:

“(...) ahora bien, los actos de conspiración importan una forma de coautoría anticipada, en cuya virtud dos o más personas se conciertan para la ejecución de un delito y resuelven realizarlos -en este caso para promover, favorecer o facilitar el tráfico ilícito de drogas-(...)".

En este mismo tenor, la Segunda Sala de Apelaciones Nacional, en la sentencia del expediente $\mathrm{N}^{\circ} 33-2015^{43}$, dijo:

36. Víctor Prado Saldarriaga, Criminalidad Organizada - Parte Especial, 137 y ss.

37. Uriel Balladares Aparicio, El delito de tráfico ilícito de drogas (Lima: IDEMSA, 2010), 46 y ss.

38. Prado Saldarriaga, Criminalidad Organizada... p.154.

39. El cuarto párrafo del artículo 296 del Código Penal dice: "El que toma parte en una conspiración de dos o más personas para promover, favorecer o facilitar el tráfico ilícito de drogas, será reprimido con pena privativa de libertad no menor de cinco ni mayor de diez años y con sesenta a ciento veinte días-multa".

40. Prado Saldarriaga, Criminalidad Organizada... p.154.

41. Alonso Raúl Peña Cabrera Freyre, Derecho Penal Parte Especial (Lima: IDEMSA. 2014), 82.

42. Ibíd., 87.

43. Disponible en: https://static.legis.pe/wp-content/uploads/2018/11/Exp.-33-2015-19-5001-JR-PE-03-Legis.pe_. pdf. Acceso el 28 de octubre del 2021. 
"La conspiración consiste en declarar punibles determinados actos preparatorios; por tanto, incorpora una forma de participación intentada en el delito en rigor, coautoría anticipada: la conspiración para promover, favorecer o facilitar el tráfico ilícito de drogas, que en buena cuenta es un forma anticipada del acuerdo común necesario para la autoría, que por lo demás pierde su relevancia específica si los autores pasan a la ejecución del delito".

Se trata, pues, de actos preparatorios criminalizados autónomamente, donde lo esencial y punible es el intercambio y acuerdo de voluntades en relación a un proyecto delictivo común: la promoción, favorecimiento o facilitación del tráfico de drogas; por consiguiente, el mero acto conspirativo es típico y punible. ${ }^{44}$ Tenemos una actividad que no admite actos preparatorios, dado que hablamos de una "conspiración para delinquir en el TID", donde el legislador ha adelantado la esfera de protección a conductas en las que ni siquiera se va a dar inicio a la etapa ejecutiva de un delito principal tendente a la afectación concreta del bien jurídico tutelado. ${ }^{45}$

Es decir, en cuanto a la forma de perfeccionarse de este delito, no necesita de un resultado lesivo ni tampoco debe ir aparejado con ciertos elementos objetivos, basta la probanza de la reunión o coordinación de dos o más personas con el propósito ventilado en el tipo legal. ${ }^{46} \mathrm{La}$ agrupación debe encontrarse de forma permanente y continuada en el tiempo, sin necesidad de que tome lugar en forma clandestina. ${ }^{47} \mathrm{La}$ razón, según la doctrina, radica en que el Estado tiene la obligación de combatir y sancionar esta conspiración que facilita el delito de tráfico ilícito de drogas, cuya finalidad es disuadir a los ciudadanos que incurran en este tipo de conductas por las graves consecuencias que acarrea. $^{48}$

Por otro lado, debemos precisar que la redacción del cuarto párrafo del vigente artículo 296, al igual que el artículo $349^{49}-\mathrm{y}$ a diferencia del artículo 17 del Código Penal español ${ }^{50}$ o chileno-, no cumple en estricto con la definición del delito de conspiración en cuanto al número de personas. Es decir, según el tipo penal, no está totalmente claro si el que toma parte de la conspiración debería hacerlo a un núcleo ya constituido de conspiradores de cuando menos dos personas o ser él quien al integrarse forma la dualidad de personas mínimas requeridas por la Ley. El tipo penal dice: "[e]l que toma parte de una conspiración de dos o más personas (...)". En aplicación de una interpretación garantista de la ley y del principio pro homine, debería entenderse que la ley se refiere en el primer sentido; es decir, que el nuevo adherente debe ser un tercer miembro que se incorpora a un acto conspirativo ya en proceso de un mínimo de

44. Prado Saldarriaga, Criminalidad Organizada... 155.

45. Luis Fernando Alberto Iberico Castañeda, Manual Auto Instructivo del Curso "Tráfico llícito de Drogas" (Lima: Academia de la Magistratura, 2021), 137. http://repositorio.amag.edu.pe/bitstream/handle/123456789/687/MANUAL\%202016.pdf?sequence=4\&isAllowed $=y$

46. Sentencia pronunciada por la Segunda Sala Penal de Apelaciones Nacional en el Expediente N 33-2015.

47. Raúl Peña Cabrera Freyre, 88.

48. Sentencia pronunciada por la Segunda Sala Penal de Apelaciones Nacional en el Expediente N 33-2015.

49. Este error ha sido suplido en la redacción del artículo 108-D, en el que se habla de delito de conspiración, pero no se hable de un mínimo de agentes. En el mismo sentido, el delito de conspiración para el terrorismo, tipificado en el artículo 6-B de la Ley 25475.

50. Artículo 17.1, del Código Penal español, señala: "La conspiración existe cuando dos o más personas se conciertan para la ejecución de un delito y resuelven ejecutarlo" 
dos personas. ${ }^{51}$ Un problema similar se presentaba con la redacción de delito de asociación ilícita para delinquir del artículo 317 del Código, antes de su modificación. ${ }^{52}$

También, otra precisión que merece hacerse es que, tal como está redactado el tipo penal, la conspiración para el TID solo se presenta en las modalidades de promover, favorecer o facilitar el tráfico de drogas hacia un tercero ajeno. Prado Saldarriaga cuestiona que el legislador haya tipificado el delito de conspiración solo respecto del delito de promoción, favorecimiento o facilitación del consumo ilegal de drogas contenido en el primer párrafo del artículo 296, pues dicha criminalización debió comprender también al tercer párrafo del artículo 296 y al tipificado en el artículo 296-B..$^{33}$ Sin embargo, de la redacción vigente, solo cuando se presentan los supuestos del primer párrafo del artículo 296 se presentará el delito de conspiración para el TID; por ende, de presentarse los supuestos del segundo y tercero párrafo, éstos serán atípicos, porque el tipo penal utiliza los verbos "promover, favorecer o facilitar" — esta redacción ha sido superada por el Proyecto del Nuevo Código Penal de mayo de $2016-.{ }^{54}$

Ahora bien, se promueve el consumo de drogas cuando el tercero ajeno no se ha iniciado; se favorece cuando se permite su expansión; y se facilita cuando se proporciona la droga a quien ya está iniciado en el consumo. La distinción del tercero ajeno es de suma relevancia, pues permite sostener —en aplicación del principio de legalidad-que los actos conspirativos realizados por una persona o personas para promover, favorecer o facilitar su propio consumo carecen de relevancia penal, esto por carecer de la finalidad para el tráfico hacia un tercero.

\section{SOBRE LA APLICACIÓN DE LAS AGRAVAN- TES DEL ARTÍCULO 297 AL CUARTO PÁ- RRAFO DEL ARTÍCULO 296 DEL CÓDIGO PENAL. ¿DELITO DE CONSPIRACIÓN PARA EL TID EN SU MODALIDAD AGRAVADA?}

En nuestra opinión, la redacción del artículo 296 carece de una correcta ubicación dogmática-normativa en la tipificación de los cuatro supuestos, pero principalmente en el último. Si bien los cuatro párrafos hacen referencia, directa o indirectamente, al tráfico ilícito de drogas, la ubicación del cuarto párrafo deviene en el mal uso de la técnica legislativa, quizás amparada en el facilismo o en el desconocimiento de lo que se entiende por el delito de conspiración. Este error ha llevado a la doctrina y a la jurisprudencia a que acríticamente interpreten al artículo 296 como un tipo base con diferentes supuestos, cuando en realidad no existe ningún estudio lógico-dogmático que lo sustente. A nuestro juicio, si bien el delito de conspiración se ubica dentro del artículo 296 con la

51. Opinión diferente tiene el fiscal Peña Cabrera Freyre, para quien bastaría la presencia de dos personas conspirantes. Véase Alonso Raúl Peña Cabrera Freyre, Tráfico llícito de Drogas y delitos conexos (Lima: Editorial Rodhas, $2^{\circ}$ ed., 2014), 130.

52. El tipo decía: "El que forma parte de una organización de dos o más personas (...)". Sobre el tema, Véase. Víctor Prado Saldarriaga, Criminalidad Organizada - Parte Especial, 76 y ss.

53. Prado Saldarriaga, Criminalidad Organizada... p.154. En su opinión, tales ilícitos relativos a suministro y tráfico de materias primas e insumos, exigen, igualmente, que la penalización de la conspiración para delinquir resulte ser una necesidad criminológica y criminalistamente relevante.

54. En el Proyecto del Nuevo Código Penal de mayo de 2016, se configura en el artículo 447 el tipo base del delito de tráfico ilícito de drogas —el equivalente al artículo 296 del vigente Código Penal—; sin embargo, en el numeral 4, tipifica el delito de conspiración para todos los supuestos del artículo 447, incluyendo a la posesión de droga numeral 2-y la comercialización de insumos o materia prima - numeral 3-. El numeral 4 del artículo 447 del Proyecto dice: "En las conductas descritas en los párrafos anteriores, el que toma parte en una conspiración de dos o más personas para el tráfico ilícito de drogas, es reprimido con pena privativa de libertad no menor de cuatro ni mayor de seis años; con sesenta a ciento veinte días multa y con inhabilitación de 4 a 6 años conforme al literal d del artículo 38". 
nomenclatura de promoción o favorecimiento al tráfico ilícito de drogas, dada su naturaleza jurídico-dogmática debe interpretarse como un delito independiente del artículo 29655; y para facilitar a los operadores jurídicos lo recomendable sería que el legislador haga una modificación y lo tipifique en un artículo distinto - por ejemplo, configurarlo en el artículo 296-D—. Además, somos de la idea de que en la legislación penal peruana no existe el delito de conspiración agravada. Entre otras razones, esbozaremos las siguientes:

\section{Principio de excepcionalidad.}

Es de aceptación unánime que la presencia social del Derecho Penal tiene naturaleza excepcional; es decir, que su injerencia está condicionada a que las otras formas de control social o disciplinas jurídicas no tengan una óptima respuesta a un determinado hecho social, fundamento del principio ultima ratio. Además, la excepcionalidad se expresa en que el Derecho Penal no sancionará cualquier tipo de agresión a un bien, sino tan solo el ataque más grave, fundamento del principio de fragmentariedad. En los dos supuestos, se trata de una exigencia de economía social, que debe buscar el mayor bien social con el menor costo. La máxima utilidad posible debe combinarse con el mínimo sufrimiento. ${ }^{56}$

Ahora, el delito de conspiración es un acto preparatorio, aunque por regla general, dada su remota peligrosidad para los bienes jurídicos, los actos preparatorios no son punibles. Sin embargo, el legislador en determinados delitos, dada su gravedad, excepcionalmente ha optado por sancionar los actos preparatorios debido a su intensidad delictiva; es un adelantamiento de las barreras de punibilidad. Es una excepción de la excepción. Esta tipología es una modalidad que el Estado ha adoptado para enfrentar a la criminalidad y constituye una muestra de la expansión intensiva del Derecho Penal, derecho de tercera velocidad o derecho penal del enemigo; en tal sentido, no cabe otra alternativa que limitar en todo lo posible su interpretación y aplicación. En el marco de un Estado Constitucional, si a las normas penales ordinarias para que tengan legitimidad se le exige pasar por el filtro de una variedad de principios, con mayor razón se debe exigir a las normas extraordinarias que sancionan actos preparatorios. Se reclama que los delitos de abstracto se usen con mayor rigurosidad, pues, si no, se corre el riesgo real de limitar indebidamente los derechos fundamentales. ${ }^{57}$

\section{Autonomía del delito de conspiración.}

La autonomía de esta modalidad delictiva radica en la misma naturaleza jurídico-dogmática de los actos preparatorios. Los actos preparatorios en el iter criminis se ubican una fase totalmente distinta de los actos consumativos o de ejecución. El Estado, con la finalidad de frenar el futuro acto delictivo, se adelanta y tiene por conveniente elevarlo a la categoría de delito como cualquier otro delito con todos sus elementos constitutivos. En los códigos penales el delito de conspiración es un delito más. Siguiendo este razonamiento, el delito

55. La problemática es semejante a la que se presenta en el delito de colusión del artículo 384. Por tradición, se entendió que este dispositivo legal tipifica el delito de colusión en su modalidad simple y agravada; sin embargo, en la reciente Casación N 542-2017-Lambayeque, emitida el 3 de mayo de 2019, la Corte Suprema ha dicho que esta clasificación es técnicamente incorrecta, que no existe el delito de colusión ni simple ni agravada; sino que el primer párrafo del artículo 384, es un delito autónomo que dogmáticamente podría operar como un delito de conspiración para la colusión. "Técnicamente, entonces, no existe ni una "colusión simple" ni una "colusión agravada" en el artículo trescientos ochenta y cuatro del Código Penal vigente, sino dos delitos afines, pero notoriamente distintos e independientes entre sí. En todo caso, la nomenclatura apropiada que debe usarse para designar a ambos hechos punibles sería para el primer párrafo de dicha norma la de conspiración colusoria y para el segundo párrafo la de colusión desleal".

56. Mir Puig, Derecho Penal... p.128.

57. Pablo Cuesta Pastor, Delitos obstáculo. Tensión entre política criminal y la teoría del bien jurídico. (Granada: Comares, 2002), 37 y ss. 
de conspiración para el TID es dogmáticamente diferente del delito de TID, si bien son dos delitos afines pero notoriamente distintos e independientes entre sí. ${ }^{58}$

Siendo así y con la finalidad de facilitar la labor de los operadores jurídicos, lo correcto sería que nuestro Código tipifique en un dispositivo legal diferente del tipo base al delito de conspiración para el TID, como lo hacen la mayoría de las legislaciones del modelo continental: Alemania, España, Colombia, Argentina, Chile, etc. El fundamento radica en que, si los actos preparatorios están muy distantes de la lesión a un bien jurídico, no pueden estar en el mismo artículo que regula conductas de un delito en su fase consumativa. No tienen el mismo grado ni la misma equivalencia. No es lo mismo traficar droga que concertarse a nivel de los actos preparatorios.

Además, en nuestro sistema penal la conspiración y el delito fin son excluyentes entre sí. El que se presente uno, hace que el otro desaparezca. En tal sentido, no será posible que se condene por ambos en simultáneo, menos aún que se les aplique las mismas agravantes con la misma intensidad, puesto que, de presentarse el inicio de la ejecución delictiva, la conspiración desaparece.

\section{Tipificación comparativa del delito de conspiración.}

Un argumento más a nuestro favor para sostener que el delito de conspiración para el TID, configurado en el cuarto párrafo del artículo
296, padece de una mala técnica legislativa, es que el artículo 296 es el único dispositivo legal que regula el delito de conspiración dentro del artículo que a su vez regula el tipo base: esto no sucede, por ejemplo, con la tipificación del delito de conspiración en otras figuras delictivas como el sicariato, que no se regula dentro del tipo base -el artículo 108-C - , sino en el artículo 108-D; igualmente el delito de conspiración para el terrorismo no se configuró dentro del tipo base, el artículo 2 del Decreto Ley 25475 , sino en su artículo 6-B. También el delito de conspiración en los delitos políticos, no se reguló en el artículo 346 —rebelión-, 347 sedición- o 348 - motín-, sino en el artículo 349. Asimismo, si observamos la legislación extranjera, por ejemplo, la alemana, española ${ }^{59}$, colombiana o argentina, no encontraremos que el delito de conspiración forme parte de la tipificación del tipo penal que configura el delito base, sino que su tipificación siempre es independiente.

\section{Principio de lesividad.}

El artículo IV del Título Preliminar del Código prescribe que la pena necesita de la lesión de o puesta en peligro de bienes jurídicos. El bien jurídico tiene un sentido positivo y negativo respecto de la intervención del Derecho Penal: positivo en el sentido que le faculta la injerencia del Estado, y negativo porque lo limita; por ello se afirma que la ponderación entre los derechos estatales de injerencia y los derechos civiles de libertad se logra con el auxilio del bien jurídi$\mathrm{co}^{60} \mathrm{El}$ poder estatal y la libertad civil deben ser

58. En términos similares, véase Víctor Prado Saldarriaga, Criminalidad Organizada... p.155.

59. En el Código Penal de España, por ejemplo, el delito de conspiración para el homicidio se tipifica en el artículo 141, dispositivo distinto de los artículos 138, 139 y 140, en los que se configura el delito de homicidio y variantes; el delito de conspiración para el delito de lesiones se configura en el artículo 151, dispositivo distinto de los artículos 147, 148 y 150, en los que se tipifica el delito de lesiones. En el mismo sentido, el delito de conspiración para detenciones ilegales y secuestros en el artículo 168; robo y extorsión, artículo 269; delitos contra la salud pública, artículo 373; rebelión, artículo 477; delitos contra la corona, artículo 488; asociación ilícita, artículo 519; sedición, artículo 548; etcétera.

60. Claus Roxin, "Protección de bienes jurídicos y libertad individual en la encrucijada de la Dogmática jurídico-penal", trad. José Antonio Caro John, Revista Peruana de Doctrina y Jurisprudencias Penales 5 (2004): 291. Para mayor información ver su libro: Derecho penal, parte general, Traducción de la segunda edición alemana por Diego-Miguel Luzón Peña; Miguel Díaz y García Conlledo y Javier de Vicente Remesel, (Madrid: Civitas, Tomo I, 2006), 50-79. 
llevados a un equilibrio, de modo que garantice al individuo tanta protección estatal cuanta sea necesaria, así como también tanta libertad individual como sea posible. ${ }^{61}$ La doctrina señala que este extremo se calcula en función de la importancia del bien jurídico protegido por la norma, así como el grado en que éste resulte lesionado o puesto en peligro ${ }^{62}$; por ello, este principio está íntimamente relacionado con el principio de proporcionalidad, dado que cuando más importante sea el bien jurídico y cuanto mayor sea su lesión, mayor será el quantum de la pena y viceversa; por lo tanto, la pena de un delito consumado, de un delito en fase de ejecución - tentativa- y de los actos preparatorios no puede ser la misma, porque la lesión al bien jurídico es en diferente nivel. Este criterio es recogido por nuestro Código, puesto que los delitos de conspiración tienen una pena conminada menor a la de los delitos-fin consumados.

En el tema que nos ocupa, siguiendo la lógica de la lesividad, no cabe afirmar que la lesión al bien jurídico en su fase consumativa — regulado en los tres primeros párrafos del artículo 296 - tenga la misma intensidad que el peligro generado en la fase de los actos preparatorios - cuarto párrafo del artículo 296-. En consecuencia, la pena tampoco debería ser la misma. Por lo tanto, sería ir en contra del principio de lesividad, por ejemplo, si a un sujeto procesado por el delito de TID con la agravante de ser miembro de una organización criminal se le imponga una pena de veinticinco años y la misma pena, a su vez, se pretenda imponer a un conspirador para el TID que haya actuado en calidad de miembro de una organización criminal, dado que la lesión al bien jurídico "salud públi- $\mathrm{ca}^{\prime 63}$ en ambos supuestos no tiene la misma intensidad. Sin embargo, si se sigue el criterio de aplicar las agravantes del artículo 297 al cuarto párrafo del artículo 296, se llega a la conclusión de que serían equivalentes; es decir, que existiría equiparación entre la lesión del bien jurídico salud pública y su puesta en peligro, pese al peligro abstracto de los actos preparatorios.

Además, es una contradicción en sí, porque si el delito de conspiración para el TID se presenta en su modalidad básica tiene una pena menor al delito del tipo base del TID; sin embargo, apenas se le aplica una agravante del artículo 297, las penas de los dos delitos dejan de ser diferentes y se convierten en equivalentes. En este caso, la pena no está en función del menor o mayor grado de afectación al bien jurídico, sino en función de si se le aplica o no una agravante.

\section{Principio de proporcionalidad.}

El artículo VIII del Título Preliminar del Código establece la necesaria vinculación entre acción y represión fundamentada en una lógica sencilla, que el daño que se produce por la imposición de una pena no puede ser mayor al daño producido por la infracción; es decir, la pena debe guardar una vínculo directamente proporcional con la gravedad del hecho delictivo contemplado en la globalidad de sus aspectos; en consecuencia, debe rechazarse el establecimiento de conminaciones penales o la imposición de penas que no conecten los fines del Derecho Penal y el hecho cometido por el delincuente. ${ }^{64}$ Este principio se expresa en dos aspectos: que la pena sea proporcional al delito, y que la medida de la propor-

61. Claus Roxin, “Protección de bienes jurídicos y libertad individual en la encrucijada de la Dogmática jurídico-penal", 292

62. Gloria Patricia Lopera Meza, Principio de proporcionalidad y ley penal (Madrid: Centro de Estudios Políticos y Constitucionales, 2006), 175 y ss.

63. Si bien se señala que el bien jurídico protegido en el delito de TID es pluriofensivo, nuestra Corte Suprema ha dicho que el bien jurídico salud pública tiene preeminencia.

64. Jesús María Silva Sánchez, Aproximación al Derecho penal contemporáneo (Barcelona: Bosch, 1999), 260. 
cionalidad se establezca en función a la nocividad social del hecho. ${ }^{65}$

Desde la argumentación jurídica ${ }^{66}$, que puede ser aplicada perfectamente al Derecho Penal, se considera que una norma que restringe derechos fundamentales debe ser inversamente proporcional a la satisfacción de otro derecho fundamental. Cuando más se restrinja un derecho, mayor debe ser la realización del otro. Siguiendo esta lógica, el principio de proporcionalidad, en virtud del cual la intervención del legislador en derechos fundamentales podrá considerarse válida, procederá siempre y cuando:

a) Persiga un fin constitucionalmente legítimo;

b) Constituya un medio idóneo para alcanzarlo;

c) Sea necesaria, al no existir otro medio menos lesivo e igualmente apto para alcanzar la misma finalidad; $y$,

d) Exista proporcionalidad entre los sacrificios y los beneficios que se obtienen con la medida legislativa.

Dicho lo anterior, conviene concluir que la aplicación de las agravantes del artículo 297 al cuarto párrafo del artículo 296, infringen el principio de proporcionalidad, pues:

a) La conspiración es un delito que pune actos preparatorios, es de peligro abstracto; siendo así, no tiene el mismo reproche social que el TID en su fase de consumación; $y$,

b) No tienen la misma gravedad. Nuestra razón nos dice en términos de peligrosidad que no es igual reunirse para acordar traficar droga que el hecho mismo de traficarla. En consecuencia, la pena a aplicarse tampoco puede ser igual.
Ahora bien, si analizamos el cuarto párrafo del artículo 296, vemos que tiene una pena conminada de entre cinco a diez años, pero con las agravantes del artículo 297, las penas aumentan de quince a veinticinco años; e incluso, si se tratase de un jefe o cabecilla de una organización criminal, la pena se incrementa en el rango de veinticinco a treintaicinco años. La lógica nos indica que, si para el delito de tráfico de drogas en su fase consumativa - delito grave- existe una pena mínima de quince años, y si se tratase de un cabecilla de una organización criminal la pena mínima es de veinticinco años ${ }^{67}$; no es proporcional que para un acto menos grave - acto preparatorio- exista la misma pena. Siguiendo el test de proporcionalidad, si bien la aplicación de las agravantes puede ser idónea - aunque es cuestionable-, no sería necesaria, porque bastaría con la pena conminada en el delito de conspiración y, peor aún, no sería proporcional, porque la privación de la libertad de hasta treinta y cinco años resulta más grave que el beneficio que se busca obtener, que en este caso sería la tranquilidad pública.

En el plano comparativo, si analizamos la legislación penal alemana, vemos que los actos preparatorios punibles como el delito de traición a la paz — sección 80-, espionaje de secretos de Estado —sección 96.1-, conformación de asociaciones criminales - sección 129-, conformación de asociaciones terroristas — sección 129.A- falsificación de moneda — sección 149—-, preparación para el secuestro — sección 234.3-; son actos punibles, pero siempre en menor proporción que el delito en sí. Igualmente con la legislación española, el delito de conspiración para el homicidio —artículo 141-, lesiones —artículo 151-, detenciones ilegales y secuestros -artículo 168-, robo y extorsión —artículo 269-, delitos contra la salud pública —artículo 373-, rebelión —ar-

65. Mir Puig, Derecho Penal... p.139.

66. Nuestro Tribunal Constitucional viene aplicando esta teoría por unanimidad.

67. La Fiscalía, en la mayoría de los casos en los que se presenta el delito de conspiración para el tráfico de drogas, está acusando con las agravantes (i) que el hecho sea cometido por tres o más personas, (ii) en calidad de miembro de una organización criminal, o (iii) ser jefe de ésta. 
tículo 477-, delitos contra la corona -artículo 488-, asociación ilícita —artículo 519-, sedición -artículo 548-, etc.; en aplicación del artículo 70, son punibles, pero en uno o dos grados por debajo del mínimo legal. Similar criterio tiene el artículo 471 del Código Penal colombiano, que sanciona el acuerdo para cometer delito de rebelión o sedición, pero la pena es muy por debajo de lo establecido en los delitos tipificados en los artículos 467 y 468 . En lógica semejante la legislación penal argentina.

\section{Naturaleza configurativa de las agravantes.}

Otro argumento muy vinculado a los principios anteriores es que la redacción actual de las agravantes en nuestro Código Penal está pensada o configurada para los delitos consumados y no para los delitos en fases previas. Nuestra Corte Suprema, en reiteradas decisiones - Casación $\mathrm{N}^{\circ}$ 1083-2017-Arequipa, N 167-2018-Lambayeque, 66-2017-Junín, entre otras- ha señalado que generalmente lo que se regula en la parte especial del Código son delitos en su fase consumada. ${ }^{68}$ En este punto se considera que la parte especial del Código regula la sanción de conductas consumadas, en que se produce la efectiva lesión al bien jurídico. ${ }^{69}$

De allí que lo previsto en dichos dispositivos legales deba interpretarse y aplicarse para los delitos consumados. Siendo así, no será aplicable a las fases previas a la consumación. Por ejemplo, en la tentativa, al momento de determinar la pena, no es posible la aplicación de la regla de los tercios establecida en el artículo 45-A, porque es- tos criterios se han establecido para los delitos consumados. ${ }^{70}$ Ahora bien, en el artículo $45-A$ se regula la regla de las agravantes y atenuantes; si estas circunstancias generales no son aplicables a la tentativa, menos lo será en la fase de los actos preparatorios. Asimismo, si las agravantes generales no son aplicables a las fases previas a la consumación - actos preparatorios, tentativa一, con igual o mayor razón no es posible la aplicación de las agravantes de la parte especial.

En base a esta precisión, nuestra Corte Suprema, para determinar la pena en los delitos en fase de tentativa, ha propuesto que la pena debe disminuirse en un tercio por debajo del mínimo legal y este sería el nuevo mínimo legal. ${ }^{71}$ El nuevo máximo legal de la pena sería el mínimo establecido para el delito consumado y en aplicación de circunstancias particulares determinarse la pena en concreto. Por lo tanto, es antimetodológico y va contra el esquema de la teoría del delito que las agravantes de la parte especial — por regla — pretenda aplicarse a fases anteriores a la consumación delictiva, porque éstas - sean generales o especiales- están configuradas para los delitos consumados.

\section{Prohibición de la analogía in malam partem.}

Mientras que la interpretación es la búsqueda de un sentido del texto legal que se halle dentro del sentido literal posible, la analogía supone la aplicación de la ley penal a un supuesto no comprendido en ninguno de los sentidos posibles de su letra, pero análogo a otros sí comprendidos en el texto legal. ${ }^{72}$ Es práctica común

68. Casación N 1083-2017-Arequipa.

69. Casación Nº 167-2018-Lambayeque.

70. Casación N 1083-2017-Arequipa. "Para la determinación judicial de la pena, en casos de tentativa, no son aplicables las reglas de los tercios previstas en el artículo cuarenta y cinco-A del Código Penal, dado que la redacción y el sentido ontológico del mencionado artículo denotan una aplicación para casos en los que se determine la sanción en los marcos de la pena legal prevista en la parte especial. Por tanto, no se puede exigir al Tribunal la aplicación de esta regla en casos de tentativa". En el mismo sentido en la Casación Nº 167-2018-Lambayeque.

71. Casación N 66-2017-Junín, Recurso de Nulidad 154-2016-Ancash, entre otras.

72. Mir Puig, Derecho Penal... p. 125. 
y hasta por costumbre se nos hace pensar que, si se indica un tipo base como antecedente, se indicará uno agravado en el consecuente. Este paradigma funciona en algunos casos donde se ha hecho un uso correcto de la técnica legislativa al momento de tipificar un delito, como por ejemplo en el delito de hurto, configurado en el artículo 180, pues nadie dudaría que es el tipo base y que el artículo 186 es el tipo agravado de hurto, ya que el mismo tipo expresamente lo dice; y de igual manera con el delito de robo, tipo base, artículo 188 y el artículo 189, tipo agravado.

La situación cambia totalmente cuando, siguiendo la misma lógica — por analogía-, ésta pretenda aplicarse a los tipos penales en los que la técnica de tipificación no ha sido debidamente utilizada — sino que se ha hecho una mescolanza de varios supuestos en el mismo dispositivo legal-, pese a que lo que se pretende tipificar no comparta la misma naturaleza jurídica. Este caso es el que se presenta en el artículo 296 del CP, supuesto tipo base del delito TID, en el que se describe por un lado un delito de tráfico $y$, por el otro, un delito de actos preparatorios - delitos autónomos uno del otro-; y en el artículo 297, supuesto tipo agravado del delito de TID, pero que no señala expresamente a cuál de los supuestos es aplicable. También ocurre en el delito de sicariato, configurado como tipo base y agravado en el artículo 108-C, pero en el artículo 108-D se tipifica el delito de conspiración para el sicariato. En ese contexto, ¿serán aplicables las agravantes del delito de sicariato al delito de conspiración para el sicariato? Similar problema se presenta con el delito de colusión simple y agravada del artículo 384, empero la Corte Suprema en la Casación №542-2017-Lambayeque señaló que el artículo 384 del Código no regula el tipo base ni el agravado del delito de colusión.

En casos como los mencionados, en que la descripción típica del tipo base y agravado no es precisa y clara, consideremos que no deben aplicarse las agravantes, porque de hacerlo se infringe el principio y garantía de prohibición de analogía in malam partem. En un Estado Constitucional no es legítimo sostener que, si en determinados casos se aplica la relación de tipo base a agravado, en los casos en los que la descripción típica sea confusa, se aplique análogamente la misma lógica. En estos tipos penales debe preferirse el análisis de su naturaleza jurídico-dogmática a la de su sumillado. Cabe resaltar que nuestra Constitución Política en el artículo 139 numeral 9, y el artículo III del Título Preliminar del Código, prohíben la aplicación de la analogía no solo para calificar el supuesto fáctico delictivo, sino también para definir la pena, lo que incluye a las agravantes.

\section{Interpretación restrictiva de las leyes que restringen derechos.}

La Constitución Política, en el artículo 139 numeral 9, prohíbe la aplicación analógica de las normas que restrinjan derechos. En este mismo sentido, el artículo VII del Título Preliminar del Código Procesal Penal señala que las normas que coacten la libertad o derechos afines deben interpretarse restrictivamente. No cabe, pues, una interpretación extensiva ni analógica de aquellas restricciones que se pudieran haber establecido como límite al ejercicio de un derecho, por lo que se exige al intérprete una comprensión de esas restricciones en la forma que más se optimice su ejercicio. Se exige a las leyes que restrinjan el ejercicio de los derechos, además de estar constitucionalmente justificadas y legalmente configuradas, que deban interpretarse siempre de forma restrictiva, precisamente por la fuerza expansiva de los derechos fundamentales. En nuestro caso, las agravantes establecidas en el artículo 297 del Código, dada la ambigüedad por el mal uso de la técnica legislativa, deben ser aplicadas restrictivamente, por lo que no existe razón para su aplicación al cuarto párrafo del artículo 296. 